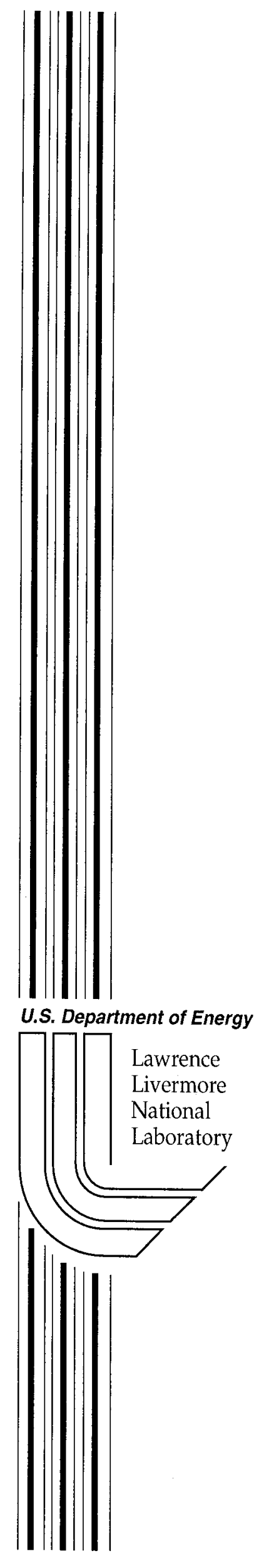

UCRL-ID-139164

\title{
Report of the National Ignition Facility Target Physics Program Review Committee
}

E. Moses

June 1, 2000 


\section{DISCLAIMER}

This document was prepared as an account of work sponsored by an agency of the United States Government. Neither the United States Government nor the University of California nor any of their employees, makes any warranty, express or implied, or assumes any legal liability or responsibility for the accuracy, completeness, or usefulness of any information, apparatus, product, or process disclosed, or represents that its use would not infringe privately owned rights. Reference herein to any specific commercial product, process, or service by trade name, trademark, manufacturer, or otherwise, does not necessarily constitute or imply its endorsement, recommendation, or favoring by the United States Government or the University of California. The views and opinions of authors expressed herein do not necessarily state or reflect those of the United States Government or the University of California, and shall not be used for advertising or product endorsement purposes.

Work performed under the auspices of the U. S. Department of Energy by the University of California Lawrence Livermore National Laboratory under Contract W-7405-Eng-48.

This report has been reproduced

directly from the best available copy.

Available to DOE and DOE contractors from the

Office of Scientific and Technical Information

P.O. Box 62, Oak Ridge, TN 37831

Prices available from (423) 576-8401

http://apollo.osti.gov/bridge/

Available to the public from the

National Technical Information Service

U.S. Department of Commerce

5285 Port Royal Rd.,

Springfield, VA 22161

http://www.ntis.gov/

OR

Lawrence Livermore National Laboratory

Technical Information Department's Digital Library

http://www.llnl.gov/tid/Library.html 


\section{Report of the National Ignition Facility Target Physics Program Review Committee \\ May 2, 2000}

\section{Introduction}

The Department of Energy's (DOE) National Ignition Facility (NIF) has been under construction at the Lawrence Livermore National Laboratory (LLNL) since 1997. This multiple-beam facility is designed to be a source of powerful focused laser light pulses for experiments in support of the nuclear weapons Stockpile Stewardship Program (SSP). NIF will be operated by LLNL as a national facility to elucidate high energy density science important to the weapons SSP and to achieving inertial confinement fusion (ICF) ignition. In addition, it will provide the nation with a valuable tool for exploring basic high energy density science. In Septernber of 1999, projected cost overruns and schedule delays were identified in the NIF project, which have necessitated development of new construction and deployment plans and schedules. These affect science programs planned for NIF and DOE programs that the NIF is meant to support.

The NIF Programs Review Committee (PRC) requested a review from this Committee of the impact of current NIF plans on the DOE SSP. The charge to the Committee is included in Appendix 1. The Committee was specifically asked to:

1. Review the current plans for the DOE Defense Programs Campaigns use of the NIF with emphasis on how to maximize the utility of the NIF to the SSP.

2. Assess the importance and timeliness to the weapons program of the planned experiments, particularly during NIF's ramp up phase.

3. Judge the overall impact of the new deployment options on the probability of the campaigns attaining their stated goals in the broadest sense.

4. Review ways of mitigating the impacts of delays, such as expanding the use of other facilities before and during the ramp up phase of the NIF, and minimizing the "learning curve" for use of the NIF.

5. Review the recent progress in ignition target physics, new ignition designs with potentially higher yield, and the utility of experiments in preparation for ignition before the facility has all 192 beams operational.

Members of the Committee were drawn from the science community, with particular knowledge of laser experiments, high energy density science, nuclear weapons, thermonuclear fusion, hydrodynamics, numerical simulation, research management, and the conduct of large experiments. A list of Committee members is in Appendix 2.

The Committee met at LLNL on April 3-4, 2000. A subset of the Committee met at LLNL on March 17, 2000 to hear briefings on ignition physics only. The meeting agendas are attached as Appendix 3. The quality of the presentations and the work they represented were extremely high. The recommendations, conclusions and findings of the Committee are presented in this report in response to the charge. 


\section{Recommendations}

1. NIF should be operated and governed as a national facility with full multi-institutional buy-in and participation, and with agreed-to management and use plans,

2. NIF should be completed to its full 192-beam configuration, with ignition as a primary objective.

3. A first cluster ( 48 beams, one-sided) should be given a high priority and brought up for experiments as soon as practical for weapons physics experiments and to attract and retain the best people.

4. Installation of beams should continue in parallel with experiments; pauses in the installation plan should occur only for budgetary necessity.

5. An overall integrated strategy and detailed plans for use of all AGEX facilities to provide weapons data should be developed.

6. The use of ICF facilities (particularly Omega and $\mathrm{Z}$ ) for improving laser-capsule coupling, new diagnostic techniques, and other weapons science experiments should be enhanced.

\section{Background}

The DOE Office of Defense Programs has developed a major change in program management strategy of the Stockpile Stewardship Program (SSP). The new plan is built upon three elements:
A. Directed Stockpile Work (DSW),
B. Campaigns, and
C. Readiness in Technical Base and Facilities (RTBF).

This structure is described in the DOE Weapons Activities Executive Budget Summary for the FY 2001 Congressional Budget request.

DSW "encompasses all activities that directly support specific weapons in the nuclear stockpile as directed by the Nuclear Weapon Stockpile Plan. These activities include current maintenance and day-to-day care of the stockpile as well as planned refurbishments as outlined by the Stockpile Life Extension Program (SLEP). Additionally this category includes research, development and certification activities in direct support of each weapon system, and long-term future-oriented research and development to solve either current or projected stockpile problems. These activities are conducted at the laboratories, NTS (Nevada Test Site), and production plants."

\footnotetext{
' DOE Weapons Activities/Executive Budget Summary for the FY 2001 Congressional Budget. This and other documents that describe the details of the elements of the SSP are available through links to the DOE Internet Web page at www doe.gov.
} 
The SSP Campaigns are "focused scientific and technical efforts to develop and maintain critical capabilities needed to enable continued certification of the stockpile for the long term. Campaigns are technically challenging, multi-function efforts that have definitive milestones, specific work plans, and specific end dates." Eleven of the 17 campaigns are shown by title below:

1. Primary Certification

2. Dynamic Materials Properties

3. Advanced Radiography

4. Secondary Certification and Nuclear Systems Margins

5. Enhanced Surety

6. Weapon System Engineering Certification

7. Certification in Hostile Environments

8. Enhanced Surveillance

9. Advanced Design and Production Technologies

10. Inertial Confinement Fusion (ICF) Ignition and High Yield

11. Defense Applications and Modeling

The other six campaigns are "Readiness" Campaigns designed to address gaps in the manufacturing infrastructure within the nuclear weapons complex.

RTBF "provides the physical infrastructure and operational readiness required to conduct the directed stockpile work and campaign activities at the laboratories, the Nevada Test Site (NTS), and the plants."

The NIF is a major element of the essential SSP experimental capability. It is expected to make substantial contributions to a number of Campaigns, as well as the DSW element of the program. In particular, contributions to Campaigns $1,2,4,7$ and 10 are anticipated. This review was established to assess those contributions in light of revised (delayed) deployment options for the facility. Descriptions of the DSW element and the five Campaigns relevant to NIF are included in Appendix 4.

Various deployment options are under consideration by DOE; two serve as deployment bounds. The first of these calls for completion of the facility as soon as possible from this point forward. This option (the so-called "Option 1") leads to the entire 192-beam machine in 2006. The second option (the so-called "Option 3") allows for completion of the full facility but with the end date delayed until 2009. In both of these cases, it is anticipated that experiments would begin as soon as construction allowed, with portions of the machine used as they become available. A chart showing the timescale for completion of these two deployment options is shown in Appendix 5. The budget implications of various options were not presented to the Committee, but given the high utility of early availability of 48-96 beams of NIF, the Committee expects that a cost effective deployment path will probably contain elements of both Options.

\section{Summary}

The benefits of NIF for the US nuclear weapons program may be categorized into four areas:

- Addressing specific stockpile issues (e.g. life extension programs, SFI investigations), 
- Establishing the credibility of the next generation of weapon "stewards," and developing a deeper scientific insight and assessment methodology, including validation of the physics models and codes used,

- Attracting, training and retaining the nation's best talent to the weapons program, and

- Maintaining the nation's pre-eminence in laser research facilities.

These four, by implication, include maintaining the US lead in the pursuit of inertial fusion energy production (IFE) using lasers, since the role of ignition and fusion burn is so important to weapons research as well as IFE.

In a notional sense, the relative utility of using parts of the facility either during the construction phase or "pausing" in the construction of NIF, are shown in the figure below. While this is not quantitative, and the Committee was not unanimous in the particulars of each line graph, it does give an indication of the relative value of subsets of NIF for the benefits we listed above. It is important to note that substantial value results from utilizing 48-96 beams. The Committee's recommendations below will call for giving a high priority to achieving early capability at this level, during the construction and installation phase.

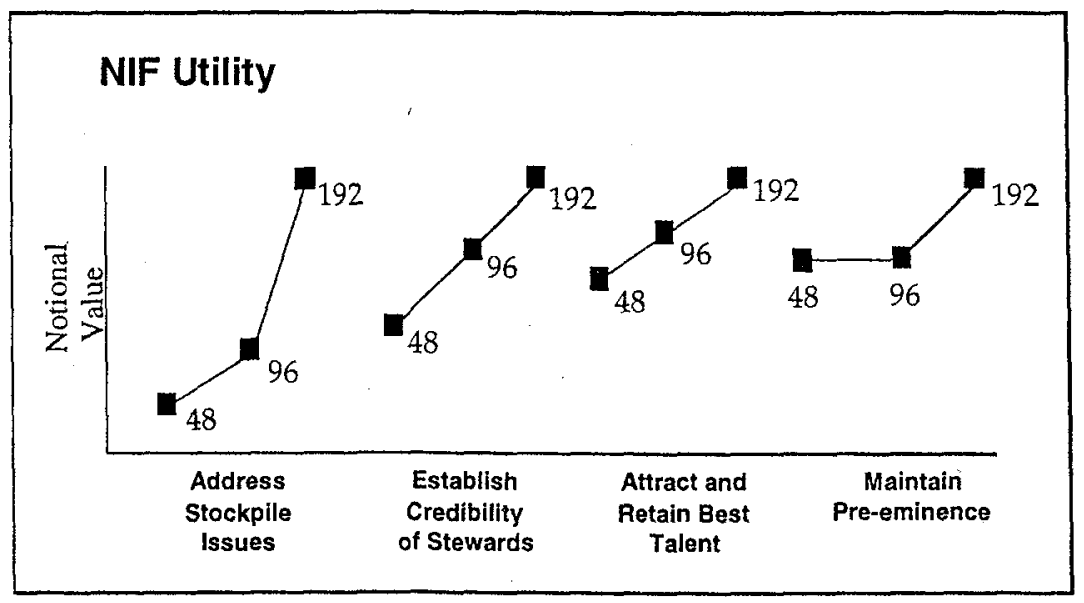

Certainly the greatest utility of NIF for all of these categories comes with ignition, and it is most likely that ignition will require the full 192 beams. Subsets of NIF also have utility. These cases are discussed in the body of the report. Finding the maximum overall utility within the budget constraints is now the problem, and we believe that the way to solve it is to develop an integrated plan for stewardship that includes personnel demographics, stockpile issues that must be addressed, and the totality of analytical and experimental resources available.

The deployment solution that provides the earliest benefit from NIF is "front loaded" in cash flow. That is, a good deal of benefit results from as early a deployment of a partial NIF as possible. There is also considerable concern that too long a delay in the deployment plan in getting to the full, or even partial NF capability could jeopardize completion of the facility at all. This is difficult to quantify. We recommend bringing up capability for target experiments as 
soon as practical and affordable, preferably on a non-interference basis with the construction and installation of additional beamlines. Operation of a first cluster ( 48 beams) will have significant benefit to the SSP DSW and Campaign programs. If a pause in construction is demanded by financial concerns, doing so at the symmetric 96-beam level provides the maximum benefit to the pursuit of the ignition mission.

All issues point to undertaking joint planning to get maximal benefit from all of the AGEX capabilities at the weapons laboratories and DOE. Operation of each facility, including NIF, should be tied to specific DSW and Campaign goals in an integrated plan. This will uncover deficiencies in the science part of the SSP, if such exist. No AGEX facility, including NIF, captures all of the physical processes that occur in either primaries or secondaries. They often cannot use the same materials or reach the same integrated conditions, and not all physical processes or parameters can be scaled individually or simultaneously. Contributions from AGEX facilities come through validation of specific aspects of the physics models and codes, which gives us increased confidence when they are applied to stockpile assessments.

\section{Responses to the charter}

\section{Review the current plans for the DOE Defense Programs Campaigns use of the NIF with emphasis on how to maximize the utility of the NIF to the SSP.}

In today's no-testing environment, NIF must be viewed as an essential facility to the SSP, because it provides the means to test relevant physics in regimes closer to where weapons function than is accessible in other planned facilities. Since Above Ground Experiments (AGEX) can both isolate physics and validate models, and also with increasing energy address more integrated experiments, NIF would be valuable to SSP even in a regime of limited testing. Nova, its smaller predecessor laser at LLNL contributed significantly, though limited in its range of experiments, while nuclear weapons underground testing (UGT) was in progress.

The committee heard plans for the use of NIF for primaries, secondaries and material properties from weapons designers from LLNL and LANL. There was enthusiasm for the use of the NIF in many areas and initial planning efforts were described. In the last decade ICF facilities, such as Nova at LLNL and more recently the Omega laser at the University of Rochester and the $\mathrm{Z}$ zpinch machine at Sandia, have had important roles in Stewardship. By extending pressure and temperature parameter space closer to that of nuclear tests, NIF will play even more important roles for both primaries and secondaries of nuclear weapons, providing both basic data and validation of codes.

For primaries, developing predictive models in regimes of high pressure and with thermonuclear burning plasmas, which require ignition, will likely be needed to address certification issues. NIF will be valuable to provide data for materials and mixtures at high pressures that are otherwise inaccessible. For example, the measurements of compressed cryogenic deuterium on Nova demonstrated that our present understanding of the simplest molecule was far from adequate. Using precise pulse shaping, data can be acquired in a broad span of equation-of-state parameter space: single-shock Hugoniot, multiple-shocked off-Hugoniot, isentropes and releases.

For secondaries, understanding the impact of surveillance findings and validating the codes are 
required for certification. NIF will provide the only facility in the absence of testing to access the parameter regimes in several areas: high temperature opacity, ultra-high pressure onHugoniot equation of states of high-Z elements, complex hydrodynamics, integrated experiments, and burning plasmas. Full NIF is required to drive hydrodynamic platforms sufficiently long to replicate and diagnose in detail the hydrodynamics in planar and convergent geometries. Ultra-high pressures can be accessed on NIF, allowing the extension of on-Hugoniot equation-of-state experiments to secondary materials. Integrated experiments will allow investigation of multiple coupled phenomena. Such experiments have already been used to provide insight into specific stockpile issues. Burn experiments will allow the investigation of coupled phenomena as well as opening up the possibility of using the additional energy created to drive more advanced experiments.

The delay in the construction project implies that NIF will have reduced impact on the current Campaign 2005 deliverables. The technical efforts of the campaigns will extend beyond 2005 , and the ultimate value of NIF to SSP is not materially diminished by the delay. In the interim, experiments at other AGEX facilities can be aligned to specific campaign objectives. Clear transitions towards the currently inaccessible physical regimes that will be opened up by NIF can be facilitated by an integrated DOE strategy that maximally utilizes other experimental capabilities during and after the NIF construction period.

Planning across the DOE complex for use of the NIF both in support of the SSP Campaigns and the DSW is not adequate at this time. Plans for such work on NIF are not as advanced as are the plans for achieving ignition. The science to be done on NIF is undoubtedly stockpile-relevant, but it needs to be tied more closely to specific weapon system certification problems, life extensions, or current and conceivable future ALTS/SFI's that need to be resolved. This will help establish timelines and tasks for NIF, better define and create excitement for the mission, get commitments from people who must work on these problems, and bind the institutions involved to a common purpose. It will also force a prioritization of developments on NIF.

The weapons laboratories should articulate common objectives and identify their differences regarding the use of all SSP/AGEX facilities. This would help refine and focus the relevance of NIF and other facilities to the SSP. We expect this activity would also result in a NIF deployment schedule that is maximally valuable to the SSP, is agreed to by all participants, is affordable, and almost certainly lies between the two options (Options 1 and 3) presented to us. Importantly, the issue of the value of NIF to primaries must be resolved within the total nuclear weapon community. LANL and LLNL should develop a common science-based strategy for what evidence they will accept in certifying primaries and develop an integrated plan for the use of NIF, as well as other facilities, for this purpose. This strategy and plan should be tailored to stockpile life-extension programs (SLEPs), known problems that must be addressed, and needs for future science and technology tools.

Perhaps the greatest value of NIF to the SSP and national security will be in engaging, recruiting, and training the next generation of weapon experts nationally. When UGTs were still being conducted, "Tests were never tests of things, they were always tests of people." (P. Jones, Director (ret), AWE.) It was their success in passing these tests that gave us the confidence that our nuclear weapons were adequate. NIF offers the opportunity for "tests" of people, the people who will be responsible for stockpile stewardship in the future. 
To this end, it is important to solicit and incorporate ideas from all DOE laboratories. Engagement of all laboratories is also important for peer review, particularly of classified weapon physics experiments. Substantial participation by the United Kingdom Atomic Weapons Establishment (AWE) is expected at NIF through collaborative experiments, possible construction of a second target chamber, or other means. The UK continues to be engaged, within classification guidelines, in planning discussions and peer review.

Use of the NIF for weapons-related experiments is very important to the SSP as soon as a section of the laser can be brought into operation without halting further construction, i.e., a "first cluster" of 48 beams brought to target from one side. It will permit important technical data to be obtained, provide a significant resource for the recruitment and retention of scientific talent, and facilitate the programmatic imperative of completing the transition from an underground test (UGT) based program to an SSP/AGEX-based program. These goals will be better served by as early as first-cluster availability as practical. While this may be of limited utility to achieving ignition, it would be important for the constitution of the necessary core teams of personnel. At 48 beams, NIF will be the largest laser in the world; it will begin to attract the best talent, and many useful experiments will be possible. The first use of a cluster will also force many of the operational issues of the laser to be addressed, so their solutions can be applied to the rest of the facility at an early stage.

Justification for the deployment of the full, 192-beam NIF complement lies, to a large degree, in the expectation and value of achieving thermonuclear burn, for which all 192 beams are, most likely, needed. Robust ignition on NIF would provide margin for controlled spoiling of the burn, which is important to the design community. The possibility of using robust ignition to undertake high-energy output radiation flow experiments would also be of significant value. Direct drive ignition capsule calculations were presented that predict high gain and robust ignition with considerable margin in required laser energy. Since adequate symmetry would be possible for direct drive experiments on NIF only after 192 beams are available, much of the initial work in direct drive experimentation should be done at Omega, as part of the overall integrated AGEX use plan.

Experiments presented to determine equation-of-state and opacity regimes relevant to both primary and secondary designs also required all 192 beams of NIF. Significant experiments for these purposes can also be performed on subsets of NIF (and on other facilities). Ignition and, if possible, robust ignition will provide exceptional value to the weapons-design community, which cannot be gained from any other AGEX technique. Indeed, with ignition, primary and secondary designers will have the ability to perform experiments in a laboratory environment that is closer to the highest pressure phase of a nuclear weapon, thereby testing their own understanding of weapon designs. The full 192-beam NIF is the only facility planned for creating these conditions.

\section{Assess the importance and timeliness to the weapons program of the planned experiments, particularly during NIF's ramp up phase.}

NIF offers the potential to provide significant weapons-related data during the ramp-up phase. There are arguments for pausing at the cluster and/or half-NIF stage to gather such data and allow time for risk reduction towards the eventual ICF goal for which experiments lasting 2-4 years have been identified. If a pause in NIF construction must be accepted for funding reasons, it should occur at a time that maximizes the opportunity to perform significant weapons-physics experiments that cannot be performed elsewhere, as well as ICF-relevant experiments to reduce 
the time to ignition once 192 beams are deployed. This would be best at 120 beams (8-fold, 2 cone) or, less usefully, at 96 beams (8-fold, 1 -cone). If this is not possible, then 48-beam (1 cluster) deployment would allow possible laser problems to be addressed at the earliest opportunity, while still supporting important weapon physics experiments. However, such pauses would delay experiments in more inaccessible physical regimes, particularly those that require ignition and burn, which provide important benefits to the weapons program. While a pause may be necessitated by budget or technical reason, there appears to be no programmatic reason related to the objectives of the SSP for pausing at a subset of the total 192 beams. A cost effective schedule for deployment of NIF should be developed and then followed.

During deployment, portions of the machine should definitely be made available for experiments as soon as practical. Such experiments are needed sooner rather than later to support Campaign deliverables and validate Accelerated Strategic Computing Initiative (ASCI) computer codes. Experience indicates it will take some time, perhaps at least one year, for experiments on a new laser to mature to the level of definitiveness. Construction should continue in parallel with experiments using the first 48 -beam cluster. For certain experiments, the 48 -beam cluster would complement other facilities; for others, it would provide a unique capability. Once again, this suggests a unified approach involving all Laboratories looking at all facilities. Another reason for a unified approach is to address the question of the sufficiency of experiments and facilities to satisfy the SSP requirements, at least in this area of physics. The value of NIF to the SSP will be greatest in the long term if the weapons designers with underground-testing experience can bring this experience to bear on NIF experiments, particularly if ignition is achieved. The age demographics of weapons designers suggests that all 192 beams be deployed while there is time for some small number of designers to transition to NIF ignition and experiments.

Since ignition at the earliest time is therefore important for SSP, the value of prior experiments should be weighed relative to achieving that goal. Some sub-ignition weapons physics experiments can be hosted on other facilities (Trident, Omega, and Z).

The leadership at LLNL and LANL in the design divisions is strong and inspiring, and has the promise to persuade staff to see the SSP mission as compelling and exciting. They can succeed in convincing the next generation of designers to "hang on" until full NIF is achieved and to accept weapons science as a career worthy of their talents. Both during ramp up and after NIF completion, a strong, visible associated science program should be nurtured. Such a program, even if modest in size, can spawn new talent, ideas, and science.

Since NIF is a national facility serving national goals, it must be operated as a community-wide user facility, even though construction and subsequent operation is the responsibility of a single laboratory. No governance plan or facility use plan was presented, although the Mission Support activity at LLNL has begun preparing the latter. Planning and decisions for future NIF access and resource allocation must reflect the national and limited international nature of its mission and goals.

\section{Judge the overall impact of the new deployment options on the probability of the campaigns attaining their stated goals in the broadest sense.}

The technology developments of Campaigns will be an enduring part of the SSP, and NIF will contribute significantly when it becomes available. Since some deployment schedules put ignition out nearly a decade or more, the greatest impact of utilization in the meantime will be to 
improve relevant data input to codes, such as EOS, opacity, and mix prescriptions, and as a validation testbed of features in ever-increasing code capabilities. Without NIF, activities will continue to do the best possible to validate codes and physics models and address SFIs with AGEX and prior UGT data. Significant progress can be made in hydrodynamics and radiation flow using Z, Omega, DARHT, and Atlas, but those facilities cannot achieve TN burn nor support experiments closer to the secondary regime. While some SFIs may be directly addressed through AGEX, SFIs that can only be addressed via simulations will benefit from more extensive and comprehensive code validation made possible by NIF experiments.

Annual certification will become a more difficult problem in 10 years and beyond, and an integrated plan is needed to develop the tools for that time frame. NIF will be an important component. It is important to develop that vision now so that a multi-lab strategy is developed, evaluated, debated, and adopted, and so complementary work on NIF and other facilities can be planned over the next 8-10 years.

4. Review ways of mitigating the impacts of delays, such as expanding the use of other facilities before and during the ramp up phase of the NIF, and minimizing the "learning curve" for use of the NIF.

A program that utilizes other, high-quality facilities, coupled with a deployment strategy for NIF, will allow quality people to be attracted and retained if a commitment to the NIF build strategy is. recognizable at DOE, LLNL, the other weapons laboratories, and Congress. A demonstrated commitment to the integrated strategy called for above would provide the recognizable support of LLNL and the other weapons laboratories necessary to allow excellent scientific talent to be attracted.

In support of SSP, significant work, especially for secondaries, can be accomplished with 48 beams. Achieving this capability in a time scale faster than Option 3 appears a good trade of value for money. Experiments at the 96-beam level (symmetrically disposed) are important to reduce the learning curve leading to ignition on the full system. As discussed above, an integrated program on weapons physics and ignition should be developed among the Labs to address specific deliverables for stockpile issues and important future stockpile relevant technology development. This plan should use all of the facilities and capabilities available to DOE, before and after NIF is completed. An outcomes-oriented plan must be formulated that addresses DOE mission requirements, without regard to facility preferences. Such a plan permits impacts of delays on both NIF and other SSP facilities to be assessed and mitigated in ways most useful to the program.

The first cluster must be deployed for use as soon as practical. There is no substitute for an inhouse capability, as a means of developing diagnostics, debugging laser operational systems, developing laser robustness at full-power operation, etc., and providing the most direct means to come up the NIF "learning curve".

Recent utilization of Omega and $\mathrm{Z}$ has been very good preparation for NIF experiments. Continued use of Omega and $Z$ will be essential, as discussed above. For example, the common diagnostic mount (TIM) allows the program to minimize diagnostic bring-up time on NIF by fully testing diagnostics on Omega and $\mathrm{Z}$. The lessons learned in the activation of Omega, along with those learned from the activation of previous lasers, can all be applied to NIF, but can only shorten the time for activation, not eliminate it. 


\section{Review the recent progress in ignition target physics, new ignition designs with potentially higher yield, and the utility of experiments in preparation for ignition before the facility has all 192 beams operational.}

The fundamental target design for ignition using NIF is substantially the same today as it was several years ago, although prospects for improved laser-target coupling efficiency have emerged recently. Following further calculations with more sophisticated computer simulation, ignition requirements were presented as unchanged with respect to:

- laser-plasma interactions (LPI), which bound the expected ignition space from above;

- the hydrodynamic behavior of the capsule, which bounds the expected ignition space from below;

- the need for a cryogenic solid DT layer initially inside a $\mathrm{CH}$, polyimide, or Be pusher;

- the required manufacturing tolerances;

- the required X-ray drive symmetry;

- the need for gas-filled hohlraums; and

- other aspects of the target and laser drive.

The first two items listed above, as coupled with the rest, primarily define the boundary in laser power-energy space for ignition. Considering the significance and the need for confidence in the expectation for ignition, more fundamental work can be undertaken to sharpen these estimates. While current computer modeling is more sophisticated in the complexity and dimensionality of phenomena incorporated and simulated, progress in embedded fundamental physics models was not discussed, for the most part. However, a number of uncertainties have been narrowed, and several significant improvements have been made in details of target design. More improvements may yet appear as other (planned) calculations address more refinements. Considerable attention has, and is yet, being given to experiments that can be performed with less than the full $192 \mathrm{NIF}$ beams to better understand, or even approach, ignition.

An unresolved issue is the laser fluence damage thresholds. The latter are presently at $\sim 4 \mathrm{~J} / \mathrm{cm}^{2}$, whereas $\sim 8 \mathrm{~J} / \mathrm{cm}^{2}$ is needed for full NIF output of $1.8 \mathrm{MJ}$. If the higher damage threshold is not achieved, expensive optics will have to be treated as consumables in high-energy shots, decreasing the number of such shots that can be supported per year for a given operating budget.

In discussing the number and schedule of NIF laser beams, sight must not be lost of the fact that what counts are the quantity and quality of energy delivered to the target capsule, including its temporal shape and spatial profile. The original NIF design conservatively assumed that less than $10 \%$ of the nominal driver energy would be absorbed by the target capsule. The facility was sized at $1.8 \mathrm{MJ}$, to provide $150 \mathrm{~kJ}$ absorbed by the capsule, with some margin. However, a number of techniques in the intervening years have emerged from the supporting R\&D program, any one of which might provide 5-20\% improvement. Taken together, these could lead to an overall improvement of a factor as high as two. As a consequence, deployment of half the beams (96), enhanced by added amplifying slabs is now calculated to provide significantly improved target performance. This presents a small chance for ignition itself, albeit with little flexibility in operating space. The 96-beam NIF might ignite at the "cliff", but would be inflexible with little or no margin for error or laser performance margin, and little or no direct-drive capability for ignition owing to issues of symmetry. Even without ignition, an adequately diagnosed 96-beam 
facility will provide significantly greater confidence in target performance. Full 192-beam deployment with this package of improvements then points toward not only ignition but also propagating burn and higher gain.

Beyond the added laser slabs, techniques promising improved coupling efficiency are as follows:

- mixtures of elements, added to the material of the hohlraum wall to increase $x$-ray albedo, decreasing the asymmetry impact of the laser-irradiated regions of the hohlraum;

- reduction of the laser entrance hole (LEH) size, either physically or via blow-off material, to reduce $\mathrm{x}$-ray energy lost from the hohlraum;

- extending the laser pulse and reducing its intensity, thereby reducing the tendency for light-scattering plasma instabilities in the hohlraum; and

- decreasing the ratio of hohlraum-to-capsule radii, directly increasing coupling efficiency.

While the expected benefits are based on simulated results, some are supported by experimental measurements. However, the experimental database is suggestive, at best, at least for the last three items. All three could be found wanting if laser-plasma interactions (LPI) reduce the fraction of light coupled into the hohlraum, although the final round of LPI experiments on Nova revealed no extraordinary problems. This agrees with the importance of the aggressive experimental program, planned across the ICF community, aimed at validating as many of these results as possible and providing data needed for better modeling prior to NIF activation. A high priority should be to provide the Omega facility at the University of Rochester with the infrastructure and capability to do relevant gas-filled hohlraums with advanced targets. Tests of candidate hohlraum wall-material mixtures will be made on Omega later this year, and should be pursued at the $\mathrm{Z}$ facility at Sandia National Laboratories as well. While improvements in $\mathrm{X}$-ray albedo are expected, experiments are needed to determine the magnitude.

Laser plasma interaction (LPI) experiments at Omega provide some confidence that allowances (25\%) taken for light scattering can be reduced, although, again, these phenomena are sufficiently complex that experiments with conditions as close to the NIF ignition configuration as possible are required. Such experiments could adequately be done with a 96-beam facility to provide high confidence in quantifying LPI losses expected in ignition experiments.

Omega implosions experiments in scaled hohlraums should continue, with improved modeling, to determine whether hohlraum dimensions can be reduced relative to the capsule, to increase energy coupling to the capsule. Experiments from Nova and Omega, and recent, larger computer simulations of plasma flow and laser light scattering suggest the use of lower laser power with longer pulse lengths and higher total laser energy to drive ignition targets. This may be efficacious and also result in less damage to laser optical components. Unfortunately, too little experimental work has been done to allow a determination of the efficacy of such designs. Continued work, even at a low level, might reveal some substantial benefit in the future.

We do not view the recent technology developments as a change of premise for a $1.8 \mathrm{MJ}$ facility. Ignition remains a high-risk challenge and conservatism is indicated for success. Implications of such high yields were not discussed, but would have a facility impact, at least in the target chamber. Cryogenic deuterium-tritium filled targets are essential for ignition with any envisioned NIF laser energies. The manufacture and characterization of such layers is proceeding adequately and we can anticipate that acceptable cryogenic capsules will be available when required for ignition experiments. However, no independent alternate means have been deployed to measure 
the surface-roughness power spectrum of the DT-ice layer inside the capsule. This should be done, as it represents such an important factor in the success of ICF. It is also important to develop techniques to measure the surface quality of frozen DT in beryllium capsules that are opaque and so cannot be probed by the techniques used for plastic targets. We encourage the investigation of the performance of cryogenic capsules at the Omega laser, even though it may be difficult to diagnose the beginnings of hot-spot formation at the center of the imploded capsule. Such experiments would serve as a driver for continued refinement of manufacturing and target transport techniques.

Alternative scenarios of illumination, including the use of $2 \omega$ (green) light and potentially more symmetric hohlraums, e.g., tetrahedrons, need eventually to be investigated. Undoubtedly other possible improvements should and will be pursued. This continues as a national endeavor. All laboratories should be engaged to propose, calculate and experimentally verify target-design features. This has occurred in the past and should be encouraged and expanded in the future. 


\section{Appendix 1}

\section{Charge to the Committee From \\ The NIF Council \\ May 25, 2000}

Dr. Damon V. Giovanielli

12 Loma Del Escolar

Los Alamos, NM 87124

Dear Dr. Giovanielli:

I am pleased to hear that you have agreed to chair the NIF Target Physics Program Review Committee. Confirming my E-mail to Dr. Joe Kilkenny of January 21, 2000, we have asked you to address the following issues relating to the impact of current NIF plans on the Stockpile Stewardship Program.

- Review the current plans for the DOE Defense Programs Campaigns use of the NIF with emphasis on how to maximize the utility of the NIF to the SSP.

- Assess the importance and timeliness to the weapons program of the planned experiments, particularly during NIF's ramp up phase.

- Judge the overall impact of the new deployment options on the probability of the campaigns attaining their stated goals in the broadest sense.

- Review ways of mitigating the impacts of delays, such as expanding the use of other facilities before and during the ramp up phase of the NIF, and minimizing the "learning curve" for use of the NIF.

- Review the recent progress in ignition target physics, new ignition designs with potentially higher yield, and the utility of experiments in preparation for ignition before the facility has all 192 beams operational.

We would appreciate receiving a report on your review by March 30, 2000. Please contact me if you need clarification or amplification of this request.

Best wishes,

John H. Birely, Member

NIF Programs Review Committee

xc: H. Grunder 


\title{
Appendix 2
}

\section{Committee Members}

\author{
David Arnett, University of Arizona \\ David Baldwin, General Atomics Corporation \\ Anthony Baxter, Atomic Weapons Establishment (UK) \\ Bill Bookless, LLNL \\ Paul Dimotakis, California Institute of Technology \\ Damon Giovanielli, Chair, Sumner Associates \\ Joyce Guzik, LANL \\ Ted Hardebeck, STRATCOM USAF \\ Joe Polito, Sandia National Laboratories \\ Barrett Ripin, Research Applied \\ Steve Rose, Rutherford Appleton Laboratory (UK) \\ Marshall Rosenbluth, University of California, San Diego
}




\section{Appendix 3}

\section{Agendas for Committee Meetings}

NIF Ignition Physics Review

Friday, March 17, 2000

B-381, Room 1336

\begin{tabular}{|c|c|c|}
\hline $8: 30-9: 00$ & Welcome and Overview & Joe Kilkenny \\
\hline $9: 00-9: 45$ & Deployment Options for the NIF & Brian MacGowan \\
\hline $9: 45-10: 15$ & $\begin{array}{l}\text { Summary of Advances in Ignition Target Design } \\
\text { Impact of Staged NIF Activation Scenarios on } \\
\text { Ignition Program }\end{array}$ & John Lindl \\
\hline $10: 15-10: 30$ & Break & \\
\hline $10: 30-11: 00$ & High Yield Story/Cocktails, etc. & Larry Suter \\
\hline $11: 00-12: 00$ & Advances in Ignition Physics Target Design & Steve Haan \\
\hline $12: 00-1: 00$ & Working Lunch & \\
\hline $1: 00-1: 30$ & Recent Progress in Target Fabrication & Tom Bernat \\
\hline $1: 30-2: 00$ & Ignition Planning under the Various & \\
\hline & Implementation Options & Bruce Hammel \\
\hline $2: 00-3: 30$ & Wrap up discussions & All \\
\hline
\end{tabular}




\section{NIF Target Physics Review}

\section{April 3-5, 2000}

Monday, April 3, 2000 -Unclassified

B-381/Auditorium

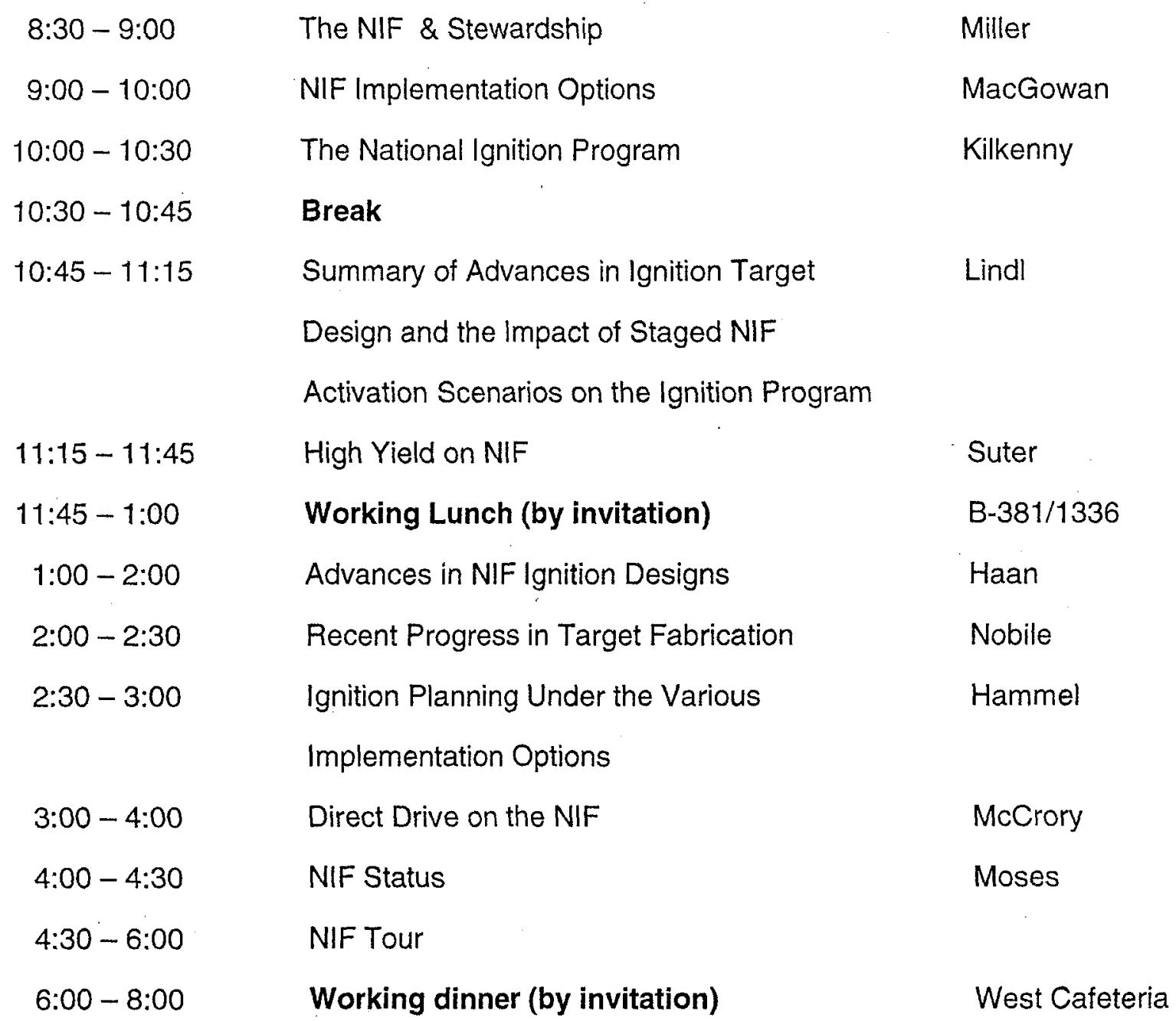


Tuesday, April 4, 2000- Q Clearance Requirer B-132N, Room 1102

\begin{tabular}{|c|c|c|}
\hline $8: 00-8: 05$ & UK Transmitability Rules & Hsing \\
\hline $8: 05-8: 35$ & The Stockpile Stewardship Drivers & Ward \\
\hline \multirow[t]{2}{*}{$8: 35-9: 35$} & Secondary Program Use of & Verdon \\
\hline & NIF \& ICF Facilities by LLNL & \\
\hline \multirow[t]{2}{*}{$9: 35-10: 35$} & Secondary Program Use of & Krauser \\
\hline & NIF \& ICF Facilities by LANL & \\
\hline 10:35-11:00 & Break & \\
\hline \multirow[t]{2}{*}{$11: 00-11: 45$} & Primary Program Use of NIF \& ICF & Goodwin \\
\hline & Facilities by LLNL & \\
\hline $11: 45-12: 45$ & Working lunch (by invitation) & B-132/1102 \\
\hline $12: 45-1: 45$ & $\begin{array}{l}\text { Materials Properties Use } \\
\text { of NIF \& ICF Facilities }\end{array}$ & Goldstein \\
\hline $1: 45-2: 15$ & Summary of Use of NIF for SSP & Ward \\
\hline $2: 15-3: 15$ & NIF Target Diagnostics & Leeper \\
\hline $3: 15-6: 00$ & Discussion & \\
\hline $6: 00-8: 00$ & Working dinner (by invitation) & West Cafeteria \\
\hline \multicolumn{3}{|c|}{$\begin{array}{l}\text { Wednesday, April 5. } 2000 \\
\text { B-381, Room } 1336\end{array}$} \\
\hline \multicolumn{3}{|c|}{ Morning: report drafting } \\
\hline
\end{tabular}




\title{
Appendix 4
}

\section{Descriptions of DSW and Campaigns 1, 2, 4, 7 and 10}

\author{
(from reference 1)
}

Directed Stockpile Work (DSW) encompasses all activities that directly support specific weapons in the nuclear stockpile. These activities include current maintenance and day-to-day care as well as planned refurbishments as outlined by the Stockpile Life Extension Program (SLEP). Additionally, DSW includes research, development, engineering, and certification activities in direct support of each weapon both in the present and future. DSW is executed through an integrated system of plans that utilize parts of the entire nuclear weapons complex including the Defense Programs (DP) Headquarters, National Laboratories, production complex, and other DP facilities. DSW represents a robust program that will ensure the future viability of the stockpile by maintaining a balanced effort of both near-term weapon activities and long-term future research and development. DSW is executed through several subordinate activities: Stockpile Research and Development; Stockpile Maintenance; Stockpile Evaluation; Dismantlement/Disposal; Production Support; and, Field Engineering Training, and Manuals.

Stockpile Research \& Development includes the scientific understanding and engineering development capabilities necessary to support near-term and long-term requirements of the nuclear stockpile. This category includes preproduction design and engineering activities; design and development of weapon modifications; technical aspects of the laboratory surveillance and flight test program; safety studies and assessments; technical analysis needed to dismantle and safely store weapons being removed from the stockpile; and development of all new weapon designs, if needed.

Stockpile Maintenance includes limited life component exchange, maintenance, and life extension activities on various weapon types in the enduring stockpile to maintain a safe and reliable weapons stockpile.

Stockpile Evaluation includes new material laboratory tests, new material flight tests, stockpile laboratory tests, stockpile flight tests, quality evaluations, special testing, and surveillance of weapon systems to assess the safety and reliability of the nuclear weapons stockpile as a basis for the Annual Certification to the President.

Dismantlement/Disposal includes all activities including safety analysis associated with weapon retirement, disassembly, component characterization, and disposal and reclamation of materials and components; the engineering, development, testing, certification, procurement, and refurbishment of containers required for interim storage; and the staging and storage of weapons, components, and materials awaiting dismantlement. 
Production Support includes quality and production supervision and control, quality assurance and production and process engineering.

Field Engineering, Training and Manuals includes costs incurred for technical training of military and contractor personnel participating in the Joint Task Group evaluations of weapons prior to complete engineering release.

The Primary Certification Campaign (1) includes experimental activities that will develop and implement the ability to certify rebuilt and aged primaries to within a stated yield level without nuclear testing. Activities include: hydrodynamic experiments, including those conducted on DARHT; subcritical experiments at the Ula complex in Nevada needed to validate simulation and modeling capabilities; other above-ground experiments, including NIF experiments; and reanalysis of past underground test results. This campaign will integrate improved computational capabilities being developed under the Defense Applications and Modeling campaign and it is interdependent with the Dynamic Materials campaign. Capabilities developed under this campaign will directly support DSW, including the B61, W80, and W76 SLEPs and certification of the W88 warhead pit rebuild.

The Dynamic Materials Properties Campaign (2) includes efforts to develop physics-based, experimentally-validated data and models of all stockpile materials under a broad range of dynamic conditions found in nuclear explosions. In the past, dynamic materials properties were often inferred from, and normalized to, integral test data on a descriptive and empirical basis. Without the availability of such integral tests, the materials models to be developed by this campaign are essential to establish predictive relationships between materials properties and stockpile performance, safety and reliability. This Campaign will provide materials data and models of actinide thermodynamic properties (with an emphasis on plutonium multi-phase equation of state and complete phase diagram) to directly support the W88 pit rebuild; the B61, W80, and W76 refurbishments; and additional pit surveillance. Initially, the Campaign will focus on stockpile materials with the highest leverage and greatest uncertainties, including actinides (with a strong emphasis on plutonium), surrogate metals, boost gas, high explosives, organics, and foams.

The Secondary Certification and Nuclear-Systems Margins Campaign (4) includes experimental and computational activities which will determine the minimum primary factors necessary to produce a militarily-effective weapon. In the past, our incomplete understanding of secondary physics required underground nuclear tests to establish the performance "margins." In the absence of underground nuclear testing, aging and remanufacturing issues require a predictive capability. The activities in this campaign will develop a validated predictive computational capability for each system in the stockpile, determine the primary radiation emission and energy flow, and determine the performance of nominal, aged, and rebuilt secondaries.

The Certification in Hostile Environments Campaign (7) will develop certification tools and microelectronics technologies required, in the absence of nuclear testing, to ensure that refurbished weapons meet the Stockpile to Target Sequence (STS) hostile environments requirements. This Campaign will develop validated computational tools for certification, reevaluate nuclear weapon hostile environments, develop radiation-hardened technologies, and demonstrate certification technologies on the W76 life extension program. 
The Inertial Confinement Fusion (ICF) Ignition \& High Yield Campaign (10) includes those activities needed to support the start of ignition implosions and enhance experimental capabilities for stewardship. Material conditions that can be reached on the NIF, together with the diagnostics available, will also provide enhanced experimental capability for weapon certification, and weapons-relevant materials dynamics measurements. X-ray-driven and directly-driven thermonuclear ignition on the NIF will provide a unique testbed for radiationhydrodynamic codes including burn propagation and mix. Achievement of ignition will be preceded by developing the ignition targets and target diagnostics, and by experiments that verify conditions produced by the laser pulses necessary for ignition. Ignited targets as well as other special targets will provide high $\mathrm{x}$-ray and neutron fluxes for hostile environment certification of weapons subsystems. The Campaign will further pursue high yield target designs on pulsedpower systems. 


\section{Appendix 5}

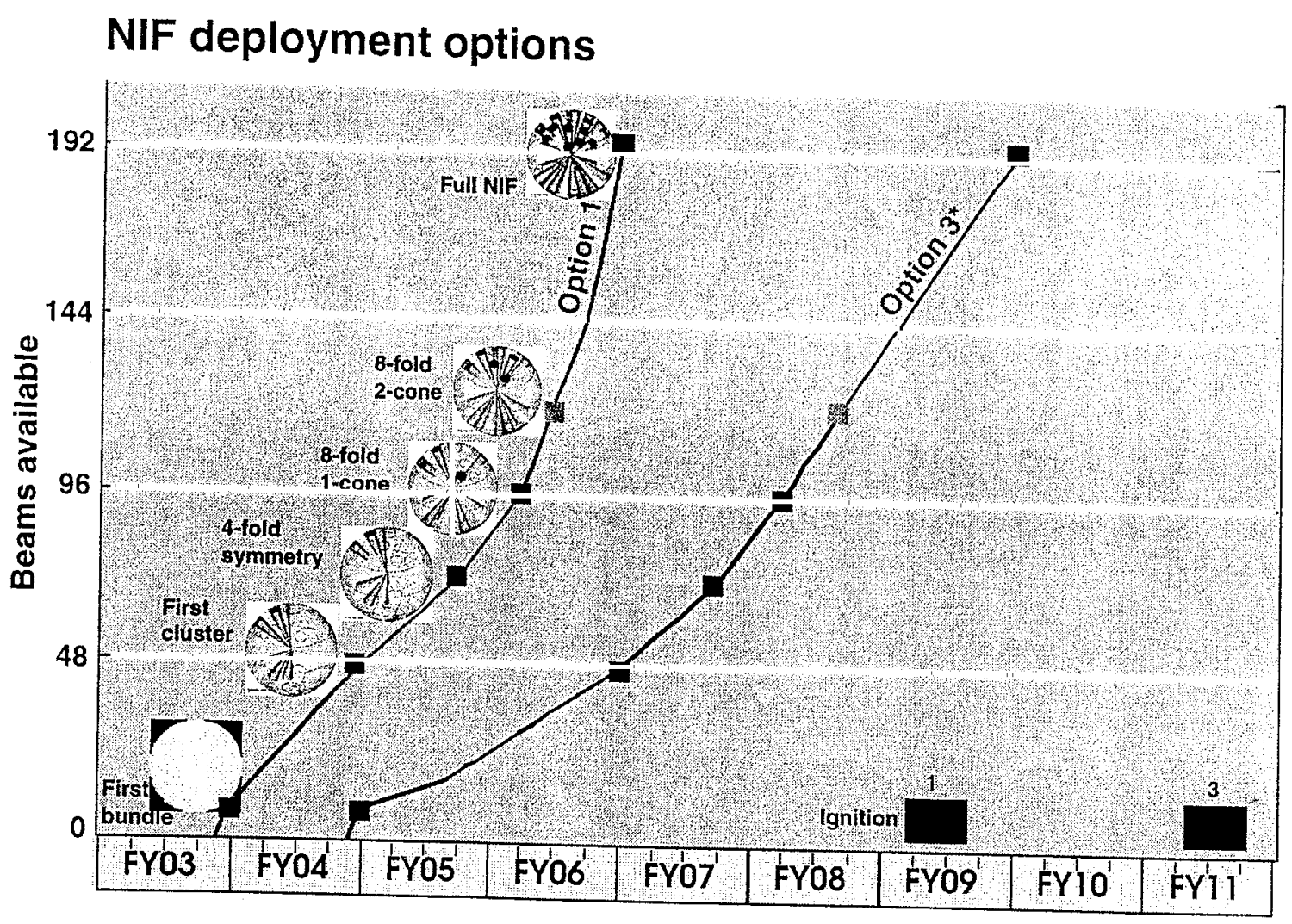


